\title{
CFD CHARACTERIZATION OF A WET FOAM FLOW RHEOLOGICAL BEHAVIOR
}

\author{
Heni DALLAGI ${ }^{1}$ \\ Dallagi.heni@gmail.com \\ UMET UMR 8207, National \\ Institute for Agricultural Research, \\ 369, Rue Jules Guesde, BP 39 \\ F-59651 Villeneuve d'Ascq Cedex \\ France
}

Christine FAILLE ${ }^{3}$

Christine.faille@inra.fr

UMET UMR 8207, National Institute for Agricultural Research, 369, Rue Jules Guesde, B.P.39, F-59651 Villeneuve d'Ascq Cedex France
Ramla GHEITH

ramla2gheith@yahoo.fr

University of Monastir, National

High Eng. School of Monastir, Laboratory LESTE, Avenue Ibn El Jazzar 5019 Monastir Tunisia

\section{Wolfgang AUGUSTIN}

w.augustin@tu-braunschweig.de Technische Universität

Braunschweig, Institute for

Chemical and Thermal Process

Engineering, Langer Kamp 7, 38106 Braunschweig - Germany

\author{
Ahmad AL SAABI ${ }^{2}$ \\ ahmad.al-saabi@inra.fr \\ UMET UMR 8207, National \\ Institute for Agricultural Research, \\ 369, Rue Jules Guesde, BP 39 \\ F-59651 Villeneuve d'Ascq Cedex \\ France
}

\author{
Thierry BENEZECH ${ }^{4}$ \\ Thierry.Benezech@inra.fr \\ UMET UMR 8207, National \\ Institute for Agricultural Research, \\ 369, Rue Jules Guesde, B.P.39 \\ F-59651 Villeneuve d'Ascq Cedex \\ France
}

\section{* Fethi ALOUI}

* Corresponding author: fethi.aloui@univ-valenciennes.fr

LAMIH UMR CNRS 8201, University of Valenciennes (UVHC), Department of Mechanical Engineering, Campus Mont Houy, F-59313 Valenciennes Cedex 9 - France

\section{ABSTRACT}

In some industrial processes, aqueous foams flow presents an important phase of the process, whereas, they cause pressure drop when designing and dimensioning systems. Identifying the different rheological parameters of foam flow is an interest key to understanding the interfacial phenomena. Actually, the difficulty to model the rheological parameters of foam flow is a major challenge.

In this study, we present a robust model to describe the foam fluid inside horizontal channels by the reverse approach of a numerical simulation (Computational Fluid Dynamics: CFD), based on the behavior laws of the Herschel-Bulkley type, for the non-Newtonian fluids. This reverse method starts from experimental (deduced from Particle Image Velocimetry (PIV) technique) results of the previous experimental work of Chovet (2015). The pressure losses measurements near-wall velocity fields, velocity profiles and the wall shear stress evolution including the void fraction from $55 \%$ to $85 \%$, are considered in order to identify the different parameters of the developed model to determine the nature of the flow, the foams rheological behavior and the foam flow regime along the length of the channel.

The numerical study (CFD) is applied for two conditions: the first one for a wet foam flow with a void fraction of $70 \%$ and a foam flow velocity of $2 \mathrm{~cm} / \mathrm{s}$ (one-dimensional regime) and the second one, for a foam quality of $55 \%$ and a flow rate of $6 \mathrm{~cm} / \mathrm{s}$. The numerical evolutions are identical to experimental ones for these same conditions. Therefore, we can conclude that the Herschel-Bulkley rheological model can correctly describe the aqueous foams fix behavior.

\section{KEYWORDS}

Aqueous foam flow, Rheology, Horizontal channels, Square cross-section, Behavior laws, Herschel-Bulkley model, Particle

\footnotetext{
1,2, 3, 4 INRA (National Institute for Agricultural Research)
} 
Image Velocimetry (PIV), Wall shear stress, Pressure losses, CFD simulations, Liquid-slipping layer, Void fraction.

\section{INTRODUCTION}

Foams admit unforeseen and nonlinear rheological behavior since it is influenced by the properties of both liquids and gases. This difficulty did not prevent foam to be a major subject of active research, due to its intensive presence in the industry field. The presence of foams is essential in cosmetics, nuclear engineering, petroleum engineering, in fire extinguishers and in food industry. In contact with the pipe walls, foam presents an important friction coefficient, which explains its use for cleaning hydraulic circuits in various industrial fields [1-2].

Rheology is the science treating the deformation and THE material flow that seeking links between the imposed stresses and the strains produced [3]. The foam is considered as an elasto-visco-plastic fluid. It can be elastic, viscous or plastic, according to the disruption that we apply [4-5-6-7]. Certainly, from one foam to another, special properties will change. Foam can be more rigid, can tolerates larger deformations, or can breaks if we try to distort it quickly. These differences come from the liquid proportion, or from the distribution of the bubbles sizes. But basically, its behavior is related to its structure, more exactly to the nature of cellular materials [8].

It appears that the foam complex structure, gives it a higher shear resistance, which is interpretable according to Camp (1988) by the existence of a yield stress. Indeed, foams require a minimum amount of energy to be in flow, when foams flowing, the stress is greater or equal to the yield stress, to which is added a viscous contribution, which depends on applied shear rate whose rheological behavior, can be described as a non-Newtonian. In a general approach, the most common models are those that consider a shear at the middle of the foam [9-10-11]. The continuum non-Newtonian models are:

$$
\text { Bingham: } \tau=\tau_{0}+k \cdot \dot{\gamma}
$$

$$
\text { Ostwald de Weale: } \tau=k \cdot \dot{\gamma}^{n}
$$

$$
\text { Herschel-Bulkley: } \tau=\tau_{0}+k \cdot \dot{\gamma}^{n}
$$

However, some previous studies show that a Bingham fluid can predict the behavior of a foam flow, only for low velocity and most of its results present a deviation of $25 \%$ and $50 \%$. Then, we consider a power law of Herschel-Bulkley model and test its efficiency to describe such flow situations [9-12].

In addition, the experimental measurements of axial velocity profiles at the lateral wall of the foam flowing inside horizontal channels, made by Blondin (1999), Tisné (2003) and Aloui and Madani (2008) helped to highlight three flow regimes whose scope depends on both the velocity of gas and of liquid, on the average velocity inside the pipe's measurement and on its geometry [13-14-15-16].

These three flow regimes are:

One-dimensional regime, the velocity vector has only one uniform axial component in the flow direction.

Two-dimensional regime corresponding to a vertically sheared flow.

Three-dimensional regime corresponding to a completely sheared foam flow.

\section{NUMERICAL PARAMETERS}

In order to simulate the foams flow inside horizontal straight channels, the Computational Fluid Dynamics (CFD) geometry dimensions, must be the same as experimental facility. Therefore, was 3D geometry formed of a tube of square crosssection of $21 \times 21 \mathrm{~mm} 2$ and a length $\mathrm{L}$ of $3.2 \mathrm{~m}$, is considered. From experimental results (Aloui and Madani, 2008), we consider velocity values, static pressure and velocity gradients corresponding to each flow regime along the channel's length. Several profiles are matched and those, which are validated, will be pulled.

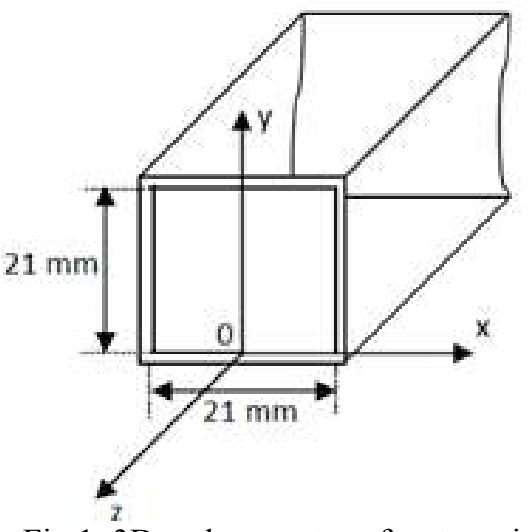

Fig.1. 3D and geometry of test-section

For constraints greater than the yield stress, and in order to simplify the study, we assumed:

- the foam behaves as a pseudo-fluid (an air-water mixture that proportions are fixed by foam quality $\beta$ ),

- non-Newtonian rheo-fluidifying behavior (Power Law index values lower than 1)

- flow with a nonlinear behavior's law which is modeled by an equation of Herschel-Bulkley that related the shear stress, with the shear strain rate, such as: 
$\frac{\partial \tau}{\partial \dot{\gamma}}=n \cdot k \cdot \dot{\gamma}^{n-1}$

$\mu=\frac{\tau_{0}}{\lambda \cdot \dot{\gamma}} \cdot k(\lambda \cdot \dot{\gamma})^{n-1}$

where $n$ is known as the power law index, $k$ the consistency index, and $\dot{\gamma}$ the shear rate. In this case, the stress does not surpass the yield stress, $\dot{\gamma}=0$.

The consistency index $\mathrm{k}$ is given by the following relationship:

$k=2.10-4 . e^{4.35 \Phi_{G}}$

The constant power law index $n$, was set equal to 0.8 , after calibrating the model with the experimental data.

Concerning the yield stress, the foam density, the molar mass, the specific heat capacity and the quality, they are respectively defined as follow:

- $\quad$ Yield stress: $\tau_{0}=3.1 P a$

- Density: $\rho_{M}=(1-\beta) \cdot \rho_{L}+\beta \cdot \rho_{G}$

- $\quad$ Molar mass: $M_{M}=(1-\beta) \cdot M_{L}+\beta \cdot M_{G}(8)$

$-\quad M_{M}=(1-\beta) \cdot M_{L}+\beta \cdot M_{G}$

$$
\begin{array}{ll}
- & C_{P M}=(1-\beta) \cdot C_{P L}+\beta \cdot C_{P G} \\
- & \beta=\frac{Q_{G}}{Q_{L}+Q_{G}}
\end{array}
$$

The setting of these parameters was not done randomly, but it was chosen after several simulations. Indeed, the power law index $\mathrm{n}$ was varied from 0 to 1 and the yield stress $\tau_{0}$ changed for each value.

Also, it is necessary to specify in the creation of the involved complex fluid model, the reference pressure, the reference temperatures and the flow nature for this problem:

- Isotherm complex fluid flow,

- Considering the effect of gravity, that can improve the drainage of liquids,

- Permanent regime: the characteristics of the fluid do not change with time,

- Laminar pseudo-complex fluid flow.

The following table 1 illustrates all properties of liquid and air for each foam quality $\beta$.

Table 1. Properties of the used fluids for foam

\begin{tabular}{|c|c|c|c|c|c|c|}
\hline $\begin{array}{c}\text { Foam quality } \\
\beta[\%]\end{array}$ & $\begin{array}{c}\text { Yield Stress } \\
\tau_{0}[\mathrm{~Pa}]\end{array}$ & $\begin{array}{c}\text { Consistency } \\
\mathrm{k}[\mathrm{Pa} . \mathrm{s}]\end{array}$ & $\begin{array}{c}\text { Power Law } \\
\text { Index } \mathrm{n}\end{array}$ & $\begin{array}{c}\text { Density } \rho \\
{\left[\mathrm{kg} . \mathrm{m}^{-3}\right]}\end{array}$ & $\begin{array}{c}\text { Molar mass } \\
{\left[\mathrm{kg} . \mathrm{kmol}_{\mathrm{M}}^{-1}\right]}\end{array}$ & $\begin{array}{c}\text { Specific heat capacity } \\
\mathrm{Cp}_{M}\left[\mathrm{~J} . \mathrm{kg}^{-1} . \mathrm{K}^{-1}\right]\end{array}$ \\
\hline 55 & 3.10 & 0.0013 & 0.80 & 449.30 & 24.04 & 2434.18 \\
\hline 60 & 3.10 & 0.0014 & 0.80 & 399.51 & 24.58 & 2275.32 \\
\hline 65 & 3.10 & 0.0015 & 0.80 & 349.72 & 25.13 & 2116.45 \\
\hline 70 & 3.10 & 0.0016 & 0.80 & 299.93 & 25.68 & 1952.59 \\
\hline 75 & 3.10 & 0.0017 & 0.80 & 250.14 & 26.22 & 1798.72 \\
\hline 80 & 3.10 & 0.0018 & 0.80 & 222.56 & 26.77 & 1639.86 \\
\hline 85 & 3.10 & 0.0019 & 0.80 & 150.56 & 27.32 & 1430.67 \\
\hline Air & $/ / / / /$ & $/ / / / /$ & $/ / / / /$ & 1.18 & 28.96 & 1004.40 \\
\hline Water & $/ / / / /$ & $/ / / / /$ & $/ / / / /$ & 997 & 18.02 & 4181.70 \\
\hline
\end{tabular}

\section{RESULTS AND DISCUSSIONS}

The results obtained from the CFD simulations are presented in terms of pressure gradients, pressure losses and velocity profiles of a foam flowing with an averaged velocity of $2 \mathrm{~cm} / \mathrm{s}$ and $6 \mathrm{~cm} / \mathrm{s}$. These results will be compared to the experimental ones obtained by PIV method (Aloui and Madani, 2008) of an aqueous foam flow under the same conditions.

\subsection{Case of One-dimensional regime ( $V=2 \mathrm{~cm} / \mathrm{s})$}

\section{- Pressure losses and pressure gradient}

Pressure losses are considered to be the most interesting of this complex fluid characteristics. 
Indeed, Aloui and Madani [9] have studied the effect of the singularity on the behavior of the foam by the determination of frictional pressure losses, upstream and downstream of the singularities. Thus, they noticed that the thickness of the film has reduced regularly under the dead zone to reach a minimum value at the entrance (below the singularity). Exceeding this section, the flow of foam comes out gradually This relaxation is accompanied by a gradual increase in the thickness of the liquid film to reach a limit value which remains stable after establishing the regime away from the recirculation zone. The increase in this thickness of the film is at the origin of gravitational drainage, which becomes more important with the acceleration of the flow going from the passage section.

Therefore, it is important to check if the calculation of the pressure distribution generated by foam flow along a horizontal channel confirms the experimental result [9]. The figure 2 shows the static pressure losses $\left(\mathrm{P}-\mathrm{P}_{0}\right)$ inside the channel.

It is clear that the variation of static pressure for all foam qualities $\beta$, generated by foam flowing throughout the channel, is linear (Fig. 2). A slight difference of pressure loss between the different foam qualities of a few Pascal are observed. From this measure, we can see the longitudinal pressure gradient curve based on the foam quality.

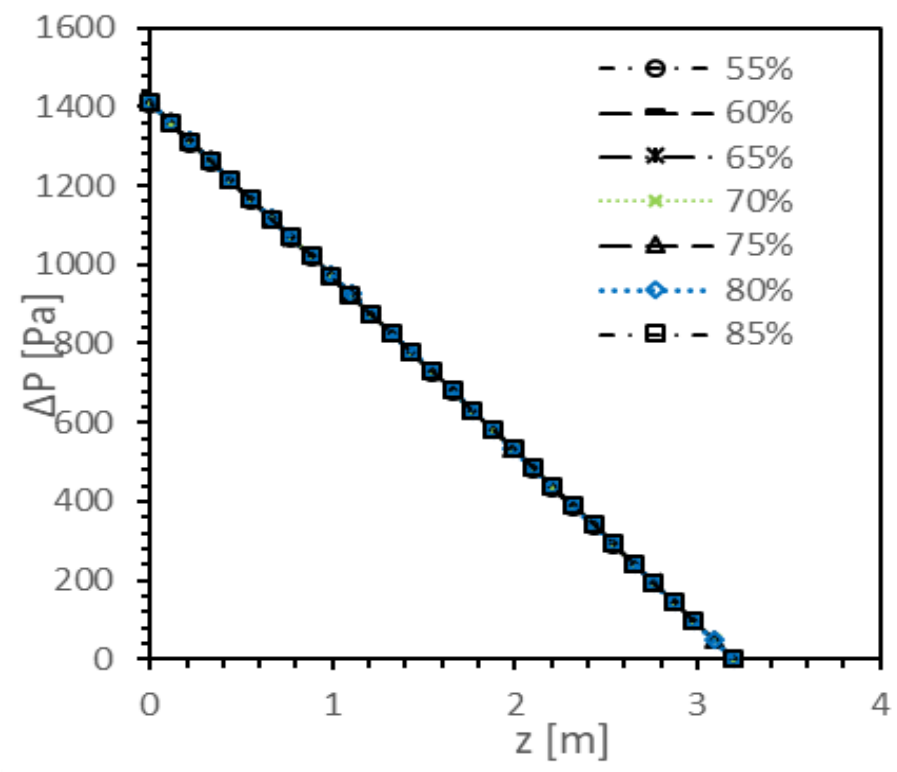

Fig. 2. Evolution of the static pressure losses of the foam flowing along the square channel for different foam quality

We note that regardless of the change in the foam quality, the longitudinal pressure gradient is also linear and it remains almost constant in the range of $440 \mathrm{~Pa}^{-1}$, which is in good agreement with the static pressure gradient obtained experimentally by Aloui and Madani (2008).

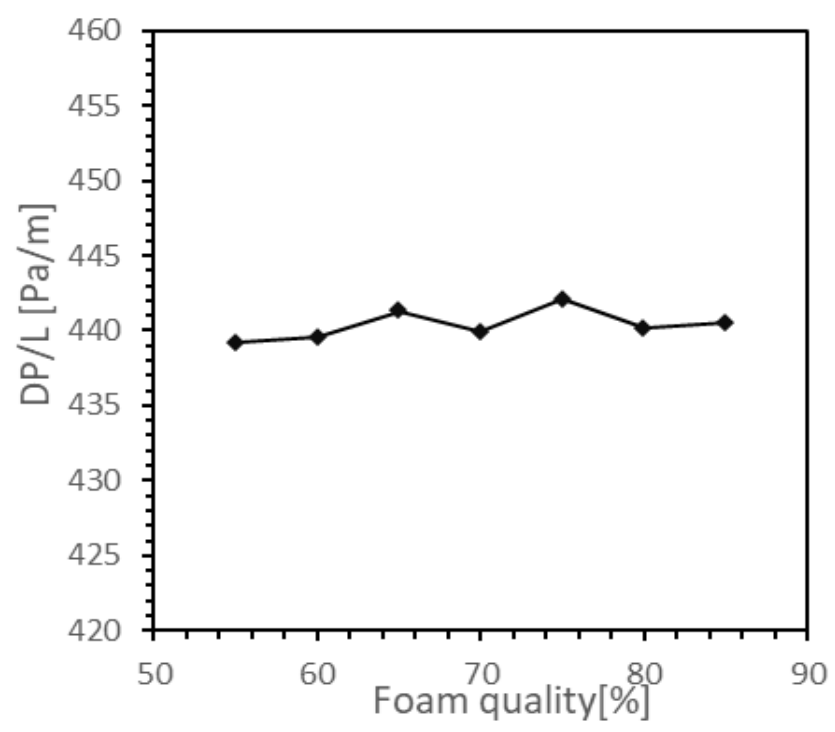

Fig. 3. Static pressure gradient for a foam flow inside a straight channel for different foam qualities

All previous experimental works of the foam flow inside a horizontal channel with square cross-section indicate that depending on the foam flow rate, this foam flow can be studied under different regimes.

Axial velocity profiles, for all the foam qualities, are presented as average velocity values in Figure 4. For different foam qualities $\beta$, the obtained velocity profiles, present an agglomerated foam flow that behaves like a block where the regime is onedimensional of a piston's type, defined by Blondin [1] in 1997. Indeed, foam's velocity is constant on the whole channel's section in agreement with the experimentation with a single generator $(2 \mathrm{~cm} / \mathrm{s})$.

However, there is a deviation of the averaged velocity profiles as a function of the fixed quality $\beta$. 
It presents a maximum for the dry foam $(\beta=85 \%)$ where the foam averaged velocity value is $\mathrm{V}=2.9 \mathrm{~cm} / \mathrm{s}$. In the case of a wet foam $(\beta=55 \%)$ it is about $1.65 \mathrm{~cm} / \mathrm{s}$. This is due to the fact that the foam's displacement is fast when the imposed gas flow rate is higher.

It is important to note that the thin liquid film between the foam and walls gives rise to a wall slip layer. This film's friction on the wall explains the slight foam's velocity reduction in contact with the film, addressed to y range, which is between $1.8 \mathrm{~mm}$ and $20.5 \mathrm{~mm}$ (the total height of the cross-section is $21 \mathrm{~mm})$.

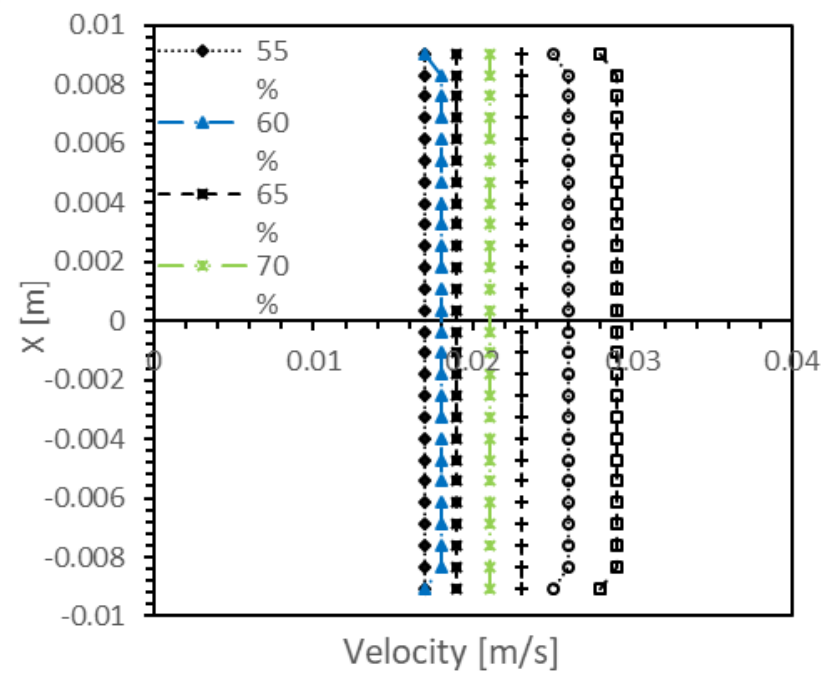

(a)

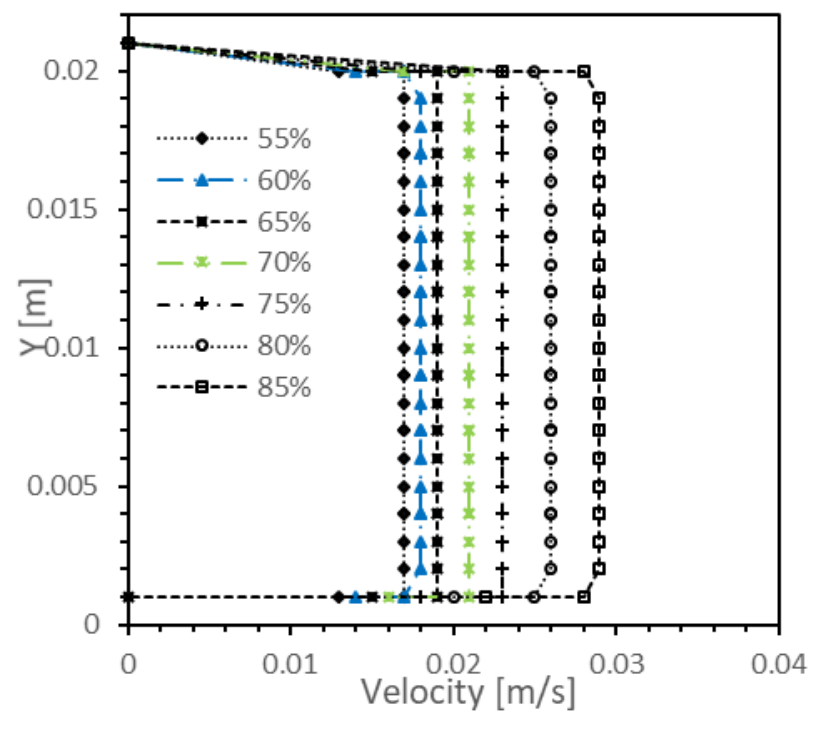

(b)
Fig. 4. Averaged axial velocity profiles' component of the foam flowing through a straight channel with different qualities

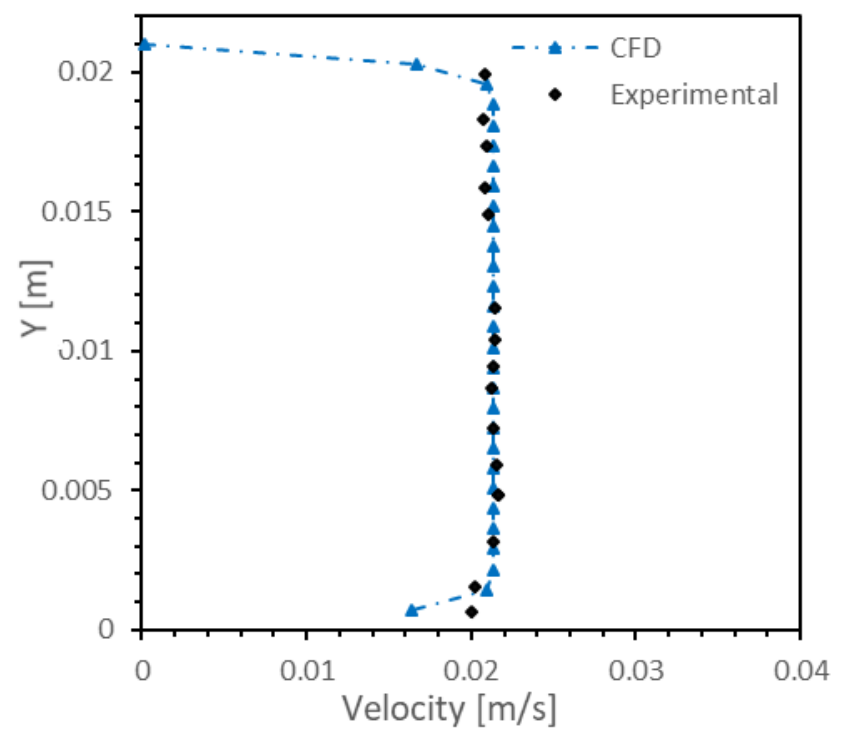

(a)

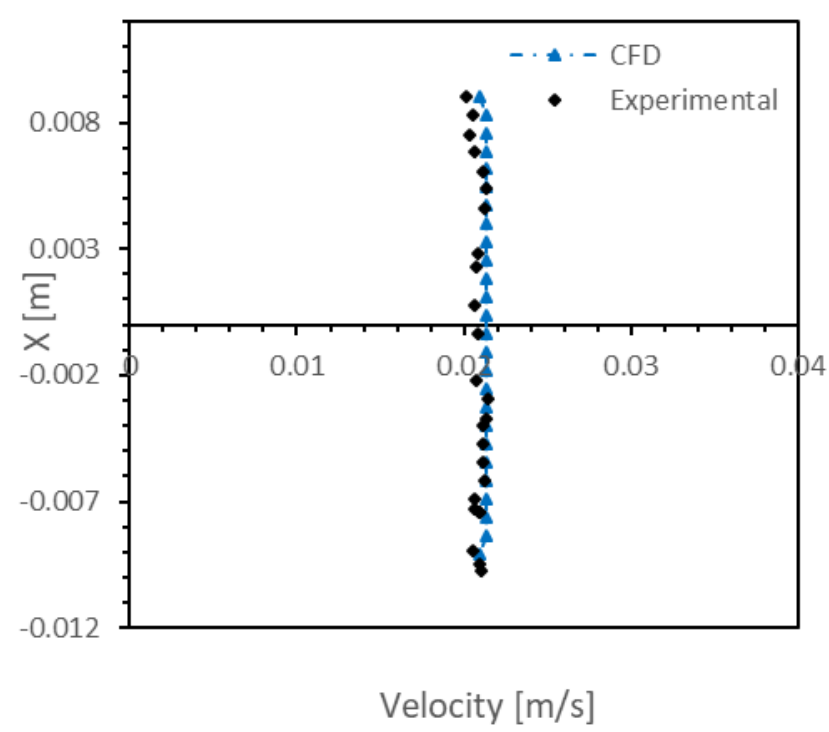

(b)

Fig. 5. Averaged axial velocity profiles for an aqueous foam with a quality of $70 \%$ and a velocity of $2 \mathrm{~cm} / \mathrm{s}$

Figures 5 above Show the axial velocity profiles evolution for a wet foam flowing with a foam quality 
of $70 \%$ and mean foam flow velocity of $2 \mathrm{~cm} / \mathrm{s}$ for their respectively Herschel-Bulkley behavior.

There, the CFD simulations matches the experimental data found in the literature. They are almost similar. These results allow validate on the one hand, the chosen boundary conditions adopted (different input and output pressure). Parameters used in this simulation, validate the chosen model, which can accurately predict and represent the onedirectional regime, for foams flow behavior for a quality of $70 \%$.

\section{- Liquid film thickness}

Based on the model of Thondavadi and Lemlich [17], we estimated the wall liquid film thickness evolution in rheology rating on the lateral wall, to determine the influence of drainage (the passage of fluid through the bubbles' contours) for all imposed qualities $(\beta)$ [18-19].

$$
\delta=\frac{{ }_{L} \cdot U_{M}}{\tau_{p}}=\frac{16 \cdot \mu_{L} \cdot L_{P} \cdot Q_{M}}{\pi D^{3} \Delta P}
$$

According to this figure (6) at the right column, we note a rising thickening of liquid film approaching to the liquid / foam interface (wall's bottom of the pipe).

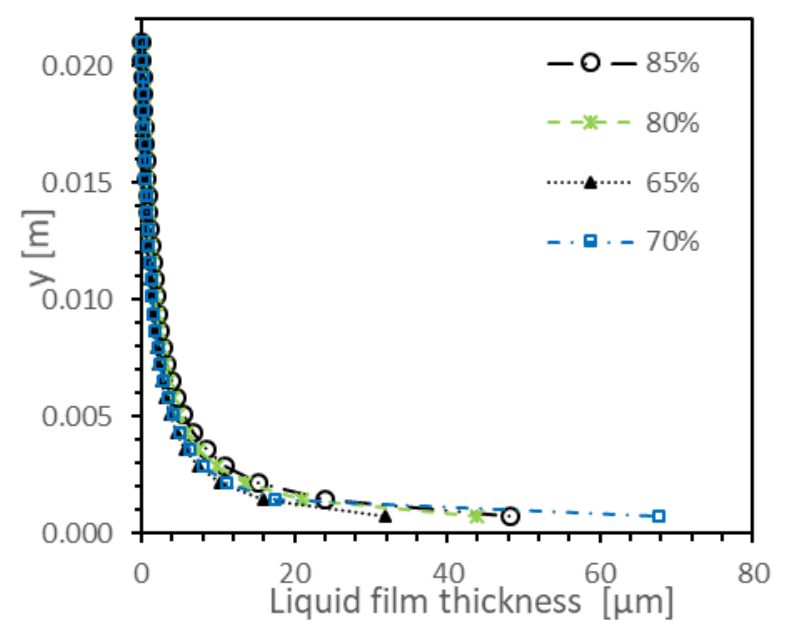

Fig.6. Estimation of the liquid film thickness the evolution on the lateral wall for all studied foam qualities $\beta$
Also, it should be noted that it varies significantly with the foam's quality: less than $50 \mu \mathrm{m}$ for the $\beta$ of $85 \%$ and $80 \%$, and in the order of $70 \mu \mathrm{m}$ for the $\beta$ of $65 \%$ and $70 \%$. Therefore, for the wettest foams, the wall slip layer is thicker than for dry layers. This is due especially to the fact that wet foams drain more liquid than dry foams.

Indeed, due to the complexity of aqueous foam flow (mixture of water and air), under the effect of gravitational force, the liquid inside the foam tends toward the pipe bottom and the gas bubbles are moved to the top of the channel. The liquid film becomes thicker in this region and gives rise to a change in the structure according to the height of the foam.

\subsection{Case of three-dimensional regime (mean foam velocity flow is $V=6 \mathrm{~cm} / \mathrm{s}$ )}

In this case we're interested in the foam's velocity profile. So, the profiles calculated out of the channel and near the lateral wall are presented in figure 7.

It is so clear that velocity profiles are not more uniform and a new flow regime appears with a completely sheared foam flow at the bottom of the channel, where the axial velocity will be also moved on the $\mathrm{x}$-direction. It is the three-dimensional regime defined in the previous works by analyzing the results obtained from PIV technique by Aloui and Madani (2008).

Due to thinner plateau borders, and weaker internal forces, dryer foams tend to shear more easily than wet foams. However, when an elevation of mean foam flow velocity $2 \mathrm{~cm} / \mathrm{s}$ to $6 \mathrm{~cm} / \mathrm{s}$, averaged axial velocity profiles of the foam flowing through a the straight channel with different qualities increases and particularly the slip layer thickness at the bottom of the channel increases.

Therefore, for this case, the foam is characterized by higher velocity at the bottom of the duct where the shear occurs and foam deforms more easily. As the average velocity is high, more the influence of the liquid film is important and the foam is subject to the 
stretching effect of liquid film flowing down with a high velocity.

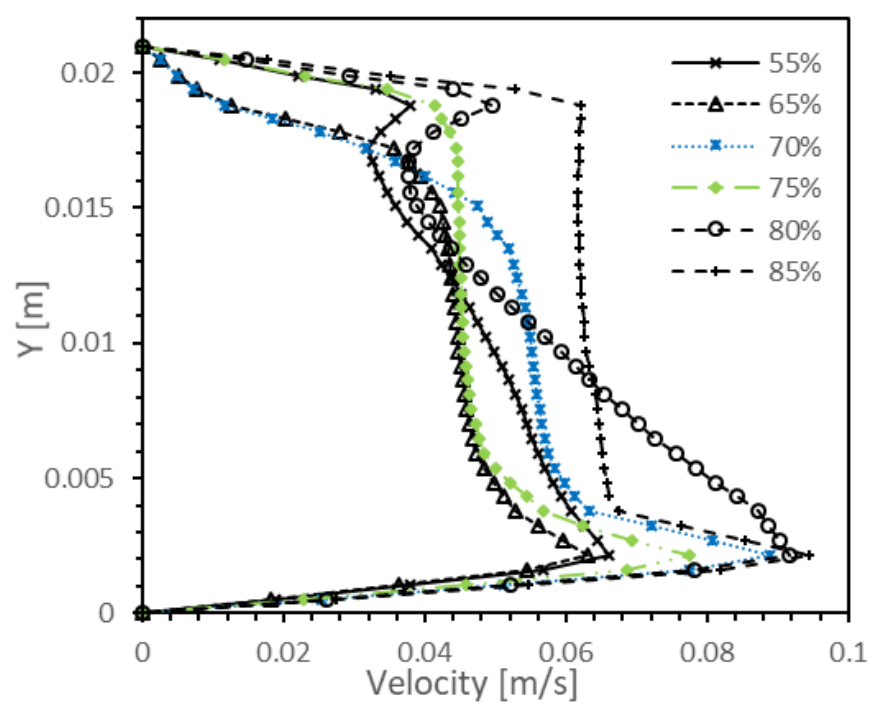

(a)

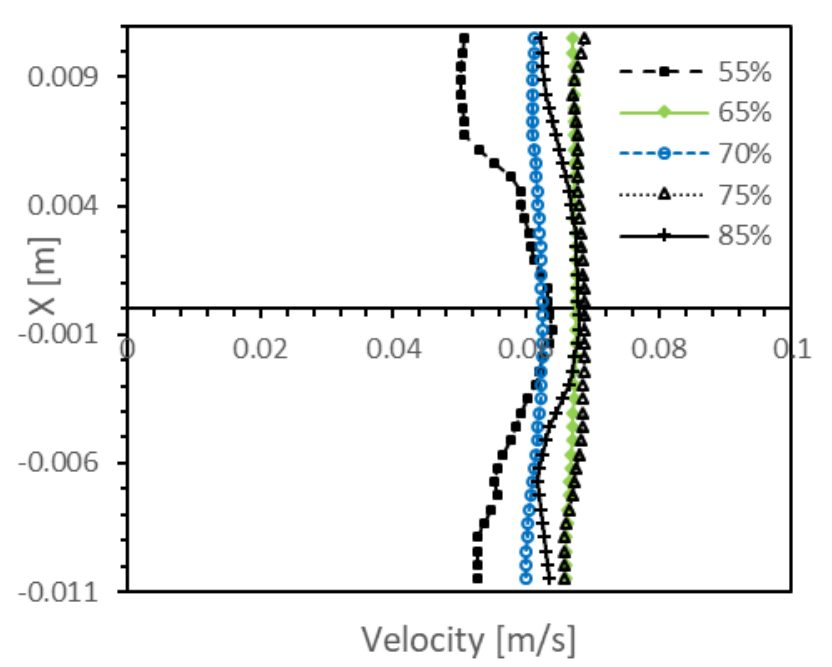

(b)

Fig.7. Averaged axial velocity profiles' component of the foam flowing through a straight channel with different qualities $\beta$

This approach seems to give values that are relevant to the experimental reality with a stretch of foam at the bottom of the duct in contact with a liquid film.

In this case (Figure 8), the agreement between the CFD numerical simulations and experimental results is still so remarkable. Comparison between the both results shows good similarity with a slight deviation. In addition, these results demonstrate the ability of the Herschel-Bulkley model to represent the threedimensional behavior for a foam quality of $55 \%$ and a velocity of $6 \mathrm{~cm} / \mathrm{s}$.

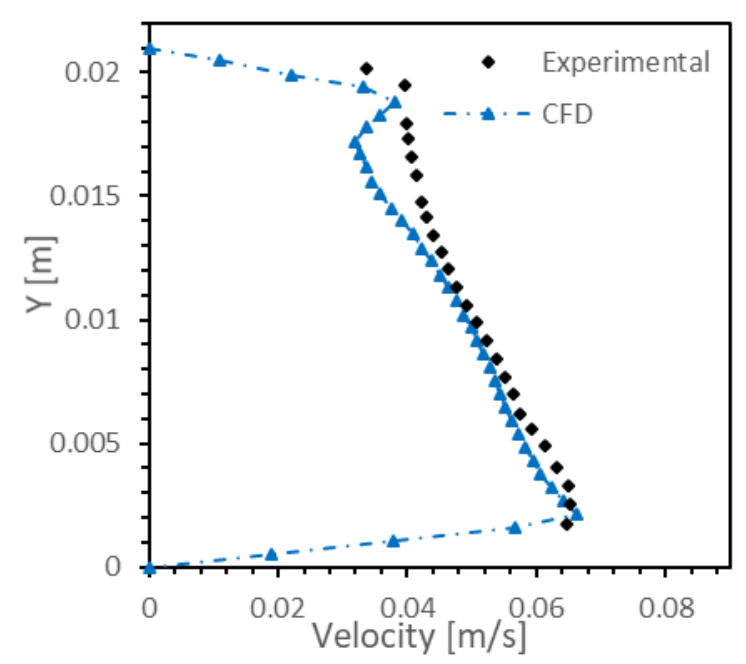

(a)

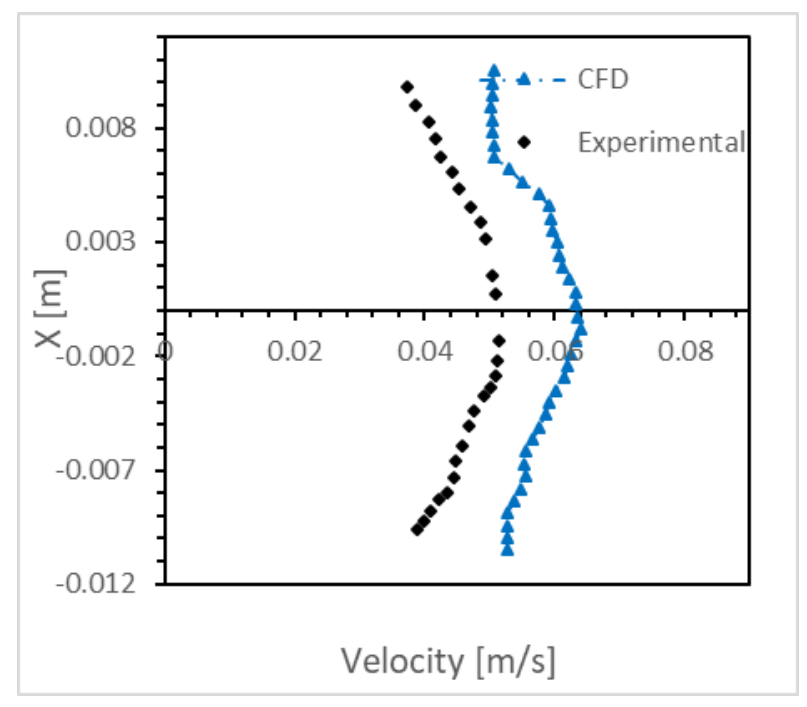

(b)

Fig.8. Averaged axial velocity profiles for an aqueous foam with a quality of $55 \%$ and a mean foam velocity of $6 \mathrm{~cm} / \mathrm{s}$

\section{CONCLUSIONS}

The presented work summarized a numerical study of aqueous non-Newtonian foam flow in a horizontal channel of square cross-section. Its goal was to 
extend the previous work of Chovet [9-12] in an interesting particular numerical model of the rheological behavior of foam flow.

The first case presents a linear static pressure gradient and a one-dimensional regime that foam at the top of the channel behave as a piston. However, for the case of three foam generators the foam flow becomes three-dimensional that velocity profile is a function of the $\mathrm{x}$-coordinate, presenting a pic at the bottom of the channel where the liquid film is thicker.

The CFD results for this numerical study of Herschel Bulkey behavior obtained either for a foam flow regime as piston type (characteristic velocity profiles), whether for three-dimensional regime (particular deviation of velocity profiles in channel's output) are very closely to the actual behavior and in relevance to the previous experimental work for these same conditions. Therefore, the Power Law rheological model can accurately describe foam behaviors and their different flow regimes.

Future trials should be conducted in order to track the foam behavior in the channel's middle and check if the Herschel-Bulkley model can be used properly to see its evolution throughout the duct. Finally, studies in regular geometry may be extended to different singularities case to be able to model the foam flow in complex situations in relevance with the geometries encountered in industrials equipment's.

\section{NOMENCLATURE}

$\mathrm{C}_{\mathrm{PM}}$ : Specific heat capacity $\left(\mathrm{J} \cdot \mathrm{kg}^{-1} \cdot \mathrm{K}^{-1}\right)$

D: Hydraulic diameter $(\mathrm{m})$

K: Consistency index (Pa.s)

L: Length (m)

$\mathrm{M}_{\mathrm{M}}$ : Molar mass $(\mathrm{kg} / \mathrm{kmol})$

N: Power Law index

Q: Volumetric flowrate (m3/s)

$\mathrm{P}_{0}$ : Static pressure at the exit of the $\operatorname{duct}(\mathrm{Pa})$

$\mathrm{P}$ : Static pressure $(\mathrm{Pa})$

$x, y, z$ : Cartesian coordinates $(\mathrm{m})$

$\beta$ : Foam quality (\%)

$\lambda$ : Time constant (s)

$\mu$ : Dynamic viscosity (Pa.s)

$\rho$ : Density $\left(\mathrm{kg} / \mathrm{m}^{3}\right)$ $\tau$ : Stress $(\mathrm{Pa})$

$\tau_{0}:$ Yield stress $(\mathrm{Pa})$

$\gamma$ : Shear rate $(1 / \mathrm{s})$

$\delta$ : Slip layer thickness (m)

$\phi_{\mathrm{G}}$ : Gas fraction (m3/s

\section{ACKNOWLEDGMENTS}

This work was supported by the laboratory LAMIH CNRS UMR 8201 (University of Valenciennes, France), the National Institute for Agricultural Research INRA (Villeneuve d'Ascq, France, laboratory UMET UMR 8207) and the laboratory LESTE (ENIM, University of Monastir, Tunisia). These supports are gratefully acknowledged.

\section{REFERENCES}

[1] E. Blondin, L. Doubliez, Particle imaging velocimetry of a wet aqueous foam with an underlying liquid film, Exp. Fluids 32 (2002) 294-301.

[2] P. Saramito. A new constitutive equation for elasto-viscoplastic fluid flows. J. Non-Newt. Fluid Mech., 145(1) (2007) 114.

[3] P. Oswald. Rhéophysique. Belin, Paris, 2005.

[4] S. Hutzler, D. Weaire. The mechanics of liquid foams: History and new developments. Colloids Surf. A, 382 (2011) 37.

[5] R.G. Larson. The Structure and Rheology of Complex Fluids. Oxford University Press, Oxford, 1999.

[6] A. M. Kraynik. Foam flows. Ann. Rev. Fluid Mech., 20 (1988) 325-357.

[7] R. Höhler, S. Cohen-Addad. Rheology of liquid foam. $J$. Phys. Condens. Matter, 17 (2005) R1041-R1069.

[8] I. Cheddadi, P. Saramito, B. Dollet, C. Raufaste, F. Graner. Understanding and predicting viscous, elastic, plastic flows. Eur. Phys. J. E. Soft matter, 34(1) (2011)11001.

[9] F. Aloui, S. Madani, Wet foam flow under a fence located in the middle of a horizontal duct of square section. Colloids and Surfaces A: Physicochem. Eng. Aspects 309 (2007) 71-86

[9] R. Chovet, Experimental and Numerical Characterization of the Rheological Behavior of a Complex Fluid: Application to a Wet Foam Flow Through a Horizontal Straight Duct with and without Flow Disruption Devices (FDD), PhD Thesis, University of Valenciennes, France.

[10] S.A. Khan, R.C., Amstrong, Rheology of foams: II. Effects of polydispersity and liquid viscosity for foams having gas fraction approching unity", J. Non-Newtonian Fluid Mech., 25 (1988) 61-92.

[11] R.G. Larson, The Structure and Rheology of Complex Fluids. New York: Oxford University Press, 1999.

[12] R. Chovet, F.Aloui, Gas-Liquid Foam through straight ducts and singularities: CFD simulations and experiments. , ASME 2014 4th Joint US-European Fluids Engineering Division Summer Meeting collocated with the ASME 2014 12th International Conference on Nanochannels, Microchannels, and Minichannels, Volume 1B, Paper No. FEDSM2014-21190, 
pp.V01BT14A003, 8 pages,Chicago, Illinois, USA, August 37, 2014, ISBN: 978-0-7918-4622-3, doi:10.1115/FEDSM201421190.

[13] P. Tisne, F. Aloui, L. Doubliez (2003). Analysis of wall shear stress in wet foam flows using the electrochemical method, International Journal of Multiphase Flow, Vol. 29 (5), 841-854

P. Tisné, L. Doubliez, F. Aloui (2004).

[14] P. Tisne, L. Doubliez, F. Aloui, Determination of the slip layer thickness for a wet foam flow, Colloids Surf. A: Physicochem. Eng. Aspects 246 (2004) 21-29.
[16] F. Aloui, S. Madani, Experimental investigation of a wet foam flow through a horizontal sudden expansion. Experimental Thermal and Fluid Science 32 (2008) 905-926

[17] N. Thondavadi, R. Lemlich, A capitance sensor for twophase liquid film thickness measurements in a square duct, Journal of Fluids Engineering 119 (1985) 164-169.

[18] A. Saint-Jalmes, D.J. Durian, Vanishing elasticity for wet foams: Equivalence with emulsions and role of polydispersity, J. Rheol. 43 (1999) 1411-1422.

[19] A. Marzec, E. Jakubczyk, Rheological properties of foams prepared for drying. Acta Agrophysica, 13 (2009) 185-194. 